\title{
PÉRDIDA O PERMANENCIA: EL ACAPARAMIENTO DE LAS TIERRAS COLECTIVAS EN CHIAPAS DURANTE EL PORFIRIATO. UN ACERCAMIENTO A LA PROBLEMÁTICA DESDE LOS EXPEDIENTES DEL JUZGADO DE DISTRITO (1876-1910)
}

\section{Justus Fenner \\ PROIMMSE-IIA-UNAM}

\begin{abstract}
RESUMEN
La historiografía mexicana posrevolucionaria ha fomentado una leyenda que responsabiliza en alto grado a las compañías deslindadoras y colonizadoras (1875-1902) de apropiarse las tierras comunales, apoyadas por el aparato judicial federal y aprovechando las leyes sobre deslindes de terrenos baldíos del Porfiriato (1876-1910).
\end{abstract}

Según esta lectura, las compañías aprovecharon su posición de agentes de gobierno en agravio de los intereses territoriales de las comunidades y de los poseedores de terrenos no titulados, usurpando así extensas tierras para su venta a particulares, mientras los jueces rechazaban los juicios de oposición. Con la actuación de las compañías deslindadoras, el proceso de desamortización de las tierras comunales, iniciado con las primeras leyes agrarias del México independiente, llegó a su punto culminante.

Confrontada esta leyenda con la documentación histórica referida al estado mexicano de Chiapas, resulta una imagen, aún preliminar, que obliga matizar la tradicional visión de un mundo indígena desentendido del mundo ladino y expuesto a las arbitrariedades del mundo oficial y de los particulares. A la vez nos ofrece un nuevo punto de vista en la interpretación tanto de la actuación de la justicia federal como de las compañías deslindadoras en el proceso de privatización de las tierras comunales. Esta perspectiva nos permite revalorar la 
evolución de la pérdida de las tierras colectivas en su justa dimensión y bajo enfoques que complementan los tradicionales.

\section{INTRODUCCIÓN}

En una nación eminentemente agrícola como fue el México decimonónico, la política de un gobierno difícilmente pudo desprenderse de los intereses de los diversos grupos sociales activos en la producción agrícola. Esta misma lógica aplicó en el ámbito estatal. Si se considera el papel del campo como el principal sostén de la política local y nacional porque genera impuestos sobre tierras y producción, abastece a la población y el comercio, y con ello, en buena medida propicia la tranquilidad y el bienestar público, parece obvio que los actos políticos de los gobiernos y de los órganos de justicia estuvieran en buena medida enfocados hacia él, encaminados a no exponer inútilmente este frágil equilibrio que mantenía vivo al Estado. El equilibrio buscado consistía en lograr el progreso material de la nación sin provocar el descontento en el medio rural, especialmente en el entorno indígena.

La desamortización de las tierras colectivas de las comunidades indígenas, promovida de diversas maneras durante todo el siglo XIX, pero especialmente a partir de las Leyes de Reforma, puso de manera particular a las instancias jurídicas en el difícil papel de proteger los intereses de las comunidades, frente a una sociedad ladina desenfrenada en su afán de apropiarse las tierras colectivas y la mano de obra barata indígena.

De 1854 en adelante, el juzgado de distrito, como instancia de la justicia federal y en su función de receptor de los denuncios de tierras baldías o nacionales, se convirtió en árbitro 
de los casos en los que reclamos sobre supuestas tierras baldías afectaron el control de las comunidades sobre sus tierras colectivas. ${ }^{1}$

\section{EL CASO DE CHIAPAS}

Conforme a la lógica arriba expuesta, las leyes agrarias que expidió el gobierno de Chiapas durante la primera mitad del siglo XIX confirmaron y respaldaron la existencia de los ejidos, limitando la desamortización a los propios de los ayuntamientos. ${ }^{2}$ No obstante, hubo usurpación de tierras comunales por parte de particulares durante los años cuarenta, especialmente de las tierras en posesión simple y no amparadas por título. El efecto negativo sobre los terrenos colectivos fue relativamente breve, y revertido en cierta medida después de poco tiempo por restituciones de ejido y compras por parte de los comuneros de propiedades mancomunadas. $^{3}$

La historiografía del Chiapas decimonónico detecta que, a partir de la promulgación de las Leyes de Reforma en 1856, encaminadas hacia la desamortización de las tierras colectivas y de las propiedades en manos muertas, se produce de nuevo un rápido proceso de pérdida de las tierras colectivas manejadas por las comunidades indígenas y un vertiginoso proceso de concentración de tierras de producción en manos de la oligarquía, conformada por un grupo reducido de personas relacionadas con las diversas funciones del gobierno, de la justicia y del comercio.

Este proceso de acumulación en detrimento de las tierras colectivas culminó en los años del Porfiriato (1876-1910), cuando las compañías deslindadoras, en unión con la oligarquía del 
estado, midieron gran parte de los terrenos baldíos y nacionales, acabando virtualmente con la propiedad colectiva, desplazando al desposeído campesino indígena de sus tierras y poniéndolo a merced de la incipiente agricultura comercial de café, hule, cacao, y de los campos madereros en las selvas vírgenes del estado. ${ }^{4}$

Una característica común de los trabajos que presentan los procesos en el campo chiapaneco durante el siglo XIX es la escasez de fuentes primarias utilizadas para sustentar sus postulados. Obviamente la conocida destrucción de varios de los principales archivos gubernamentales en 1863 y 1917 no favoreció el estudio directo de dichas fuentes. ${ }^{5}$ Los pocos documentos sobrevivientes, casualmente salvados y resguardados en los archivos restantes, se encontraban fuera de su contexto institucional, lo que complicaba su utilización referencial en la interpretación de procesos políticos y sociales.

La escasez de fuentes primarias o su poca accesibilidad tuvo como consecuencia una historiografía del siglo XIX plagada de generalizaciones y supuestos que aludían a resultados de la investigación histórica obtenidos en otras partes de la república; se limitaba al estudio de las leyes sin analizar su aplicación o bajar a la esfera de la vida cotidiana, lo que ha conducido a una visión homogenizadora entre Chiapas y el resto de México que nulifica la riqueza de lo específico, lo diferente de la historia del estado más allá de lo aceptable.

Básicamente son cuatro los momentos de la historia agraria del Chiapas decimonónico que la historiografía toma como puntos referenciales. Cuatro momentos que los mismos 
historiadores utilizan para construir una supuesta continuidad en el acaparamiento de las tierras colectivas de las comunidades durante el siglo XIX:

- $\quad$ La legislación agraria de los años 1826 y 1827 , protectora de las tierras colectivas de las comunidades, fue seguida durante los años cuarenta y cincuenta por una iniciativa de rapiña cuando particulares, funcionarios públicos y miembros del clero, acapararon las tierras comunales y baldías. Particularmente en las Prefecturas del Centro y de Comitán, donde se ubicaba la mayor parte de la población indígena, quien sufrió el impacto de la acumulación de tierras en manos de la camarilla política del estado, en detrimento de las comunidades.

- $\quad$ El segundo momento se sitúa más de veinte años después, en la llamada "guerra de castas", que se ubica con antecedentes y hasta su punto final desde 1867 a 1870; interpretada como consecuencia lógica y directa del acaparamiento de las tierras colectivas por parte de los ladinos.

- $\quad$ El tercer momento es la llegada de las compañías deslindadoras a Chiapas a partir del año 1881. Estas empresas que desarrollaron mayor actividad en el estado desde 1886 —especialmente Luis Hüller y Cía y Mexican Land and Colonization Company- estaban entre las que, en el ámbito nacional, lograron una triste fama como monopolizadoras de tierras baldías y acaparadoras de tierras colectivas de las comunidades indígenas, por lo que los autores presumen el mismo efecto sobre las tierras de Chiapas.

- $\quad$ El cuarto momento se ubica ya en el siglo XX, en enero de 1915, cuando el gobierno de Venustiano Carranza publica su ya famosa ley agraria, en la cual hace una descripción general de las causas que, según la lectura del gobierno, habían 
originado una precaria y conflictiva situación en el campo de las diferentes partes de la nación mexicana, mencionando expresamente a las compañías deslindadoras.

La historia agraria decimonónica de Chiapas fue construida con estos cuatro momentos. Resultó creíble porque parecía confirmar las experiencias habidas en otras partes de México, principalmente en el centro y norte del país. No obstante, una reciente publicación e investigaciones actualmente en marcha me conducen hoy a intentar matizar, diferenciar y someter a una reconsideración crítica las conclusiones presentadas por una historiografía especulativa. La comentada publicación de Robert H. Holden, en 1986, que se basa en una amplia revisión de la documentación de la antigua Secretaría de Fomento, arrojó información referente a Chiapas diametralmente opuesta a todo lo mantenido durante décadas. Aunque con muchas reservas, por no haber podido revisar toda la documentación, Holden mantiene que las compañías deslindadoras no contribuyeron al supuesto despojo de las tierras comunales, fueran tituladas o no, sino que respetaron las posesiones efectivas. (Holden, Robert H., p.282) ${ }^{6}$ Lo anterior, unido a los resultados preliminares de una investigación minuciosa ${ }^{7}$ de los expedientes resguardados en el archivo del Juzgado de Distrito de Chiapas, hasta hace poco considerados como perdidos, aportan hoy una visión, aún preliminar, sobre la problemática desde la documentación de dos instancias federales: el Juzgado de Distrito de Chiapas y la Secretaría de Fomento. ${ }^{8}$ Ambas permiten presentar una versión distinta de los acontecimientos en el campo del Chiapas decimonónico, revirtiendo en buena medida la imagen de las comunidades como indefensas y despojadas de sus tierras de uso colectivo. ${ }^{9}$ 
EL ARCHIVO DEL JUZGADO DE DISTRITO DE CHIAPAS, RAMO CIVIL

Si se toma en cuenta el total de los archivos judiciales existentes en el estado, el del archivo del Juzgado de Distrito solo representa una pequeña parte de este nuevo mundo documental que actualmente se está abriendo a la investigación; respecto a la cuestión que aquí interesa: los denuncios de tierras baldías o nacionales, de excedencias y demasías de terrenos ya titulados, y los pleitos que surgieron entre los mismos propietarios y especialmente entre propietarios y comunidades, estas últimas como poseedoras de tierras colectivas, el archivo del Juzgado de Distrito debe ser considerado como la fuente documental más importante y más completa en el estado. ${ }^{10}$ La intervención del Juzgado de Distrito en estos casos se debe a que para poder apropiarse legalmente de los terrenos en disputa con los ejidos, los aspirantes a poseerlos tenían que denunciarlos como baldíos, esto es, como propiedad de la nación, para que ésta, en caso de un fallo a favor, se los adjudicara. ${ }^{11}$

A pesar de que el Juzgado de Distrito inició labores en Chiapas desde 1827, durante los primeros treinta años de independencia los asuntos relacionados con tierras nacionales fueron manejados primordialmente por las instancias del gobierno estatal, a cargo de los juzgados de primera instancia, las prefecturas, la tesorería general y la secretaría de gobierno. La decisión de presentar los casos en las instancias estatales o federales se manejaba aparentemente según voluntad del denunciante. El total de denuncios relacionados con tierras nacionales que fueron manejados por el entonces juez de distrito se limita a treinta y seis casos en los mismos treinta años. No fue sino hasta 1853 cuando ese pleito latente entre los diferentes niveles de gobierno llegó a su punto final, al declarar el gobierno de López de Santa Anna, de manera definitiva, las tierras baldías y nacionales 
como propiedad del gobierno federal. ${ }^{12}$ Hasta entonces las autoridades estatales se habían considerado con el derecho de disponer de los terrenos baldíos como parte del erario, igual que el gobierno federal pugnó por defender su derecho sobre las tierras heredadas de la Colonia, con el mismo interés de consolidar sus ingresos a través de la venta a particulares.

Decretados los terrenos baldíos propiedad exclusiva de la federación, de allí en adelante los únicos responsables ${ }^{13}$ para recibir los denuncios, iniciar el apeo y deslinde de los terrenos, sentenciar los juicios de oposición y dictaminar la adjudicación al interesado, eran los jueces de distrito con el apoyo del promotor fiscal, mediante la canalización de los expedientes al Ministerio o la Secretaría de Fomento como instancia federal que aprobaba y finalmente extendía los títulos de propiedad. ${ }^{14}$

Denuncios de tierras que involucran tierras ejidales entregados al Juzgado de Distrito de Chiapas 1820-1910

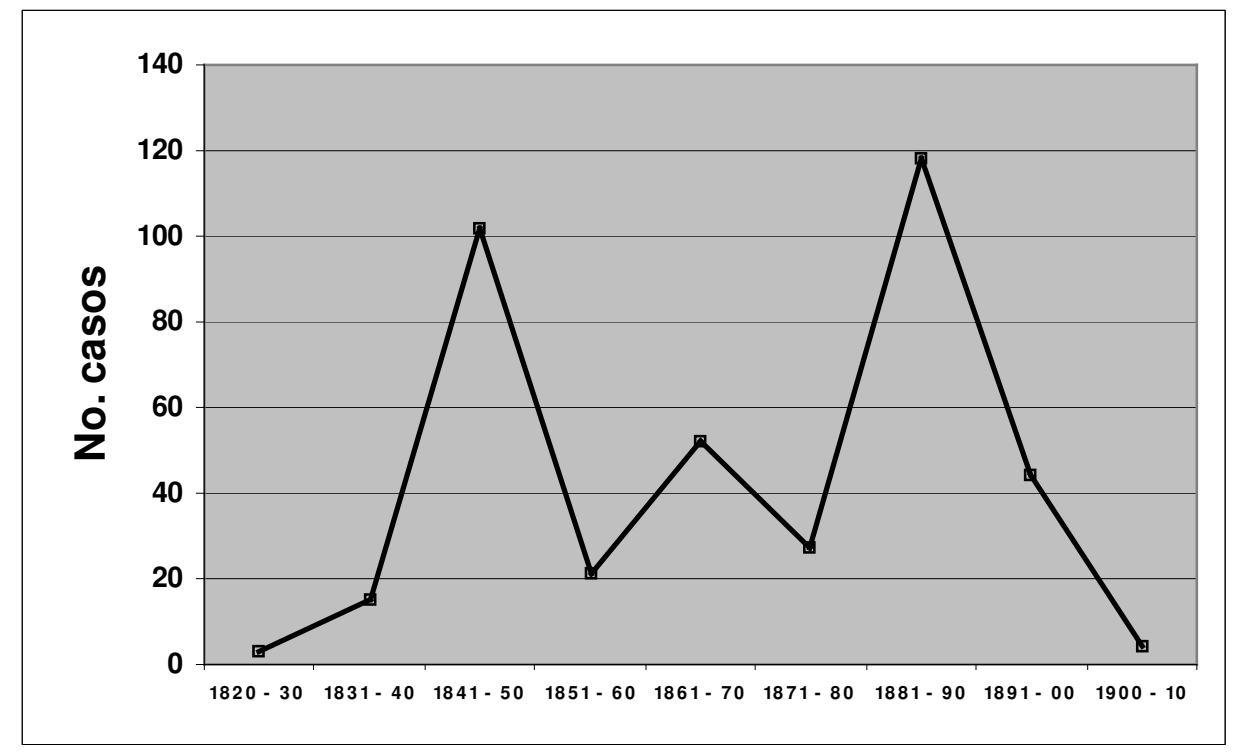

Fuente: Archivo JD. Ramo Civil. Chiapas. 


\section{EL ANÁLISIS DE CASOS}

El análisis que se presenta abarca los expedientes del ramo civil del Juzgado de Distrito de Chiapas (en adelante JD), entre los años 1876 y $1910,{ }^{15}$ partiendo del supuesto de que los casi 34 años del gobierno porfirista, con sus diversas disposiciones legales, fueron los que más graves efectos tuvieron sobre la propiedad colectiva. ${ }^{16}$

De un total de 1,485 expedientes iniciados durante el Porfiriato, referidos a la cuestión de tierras: denuncios de tierras nacionales o baldías, de demasías y excedentes que resultaron de las remedidas de propiedades existentes, solicitudes de reposición de documentos referentes a trámites o títulos extraviados; solo 346 expedientes, $23.2 \%$, corresponden a casos que involucran a comunidades, fuera como colindantes de un terreno denunciado como supuestamente baldío o como dueñas o poseedoras de una propiedad o posesión colectiva, esta última amparada por título legal o por la posesión pacífica durante tiempo inmemorial. La mayor parte de los denuncios presentados se ubican en la primera década del Porfiriato (1876-1886) con una notoria tendencia posterior al decrecimiento, llegando a un total de trece casos durante la década 1900-1910. 
Expedientes relativos a denuncios de tierras ejidales y colindancias en relación con el total de expedientes de denuncios en el JD-Chiapas, 1876-1910

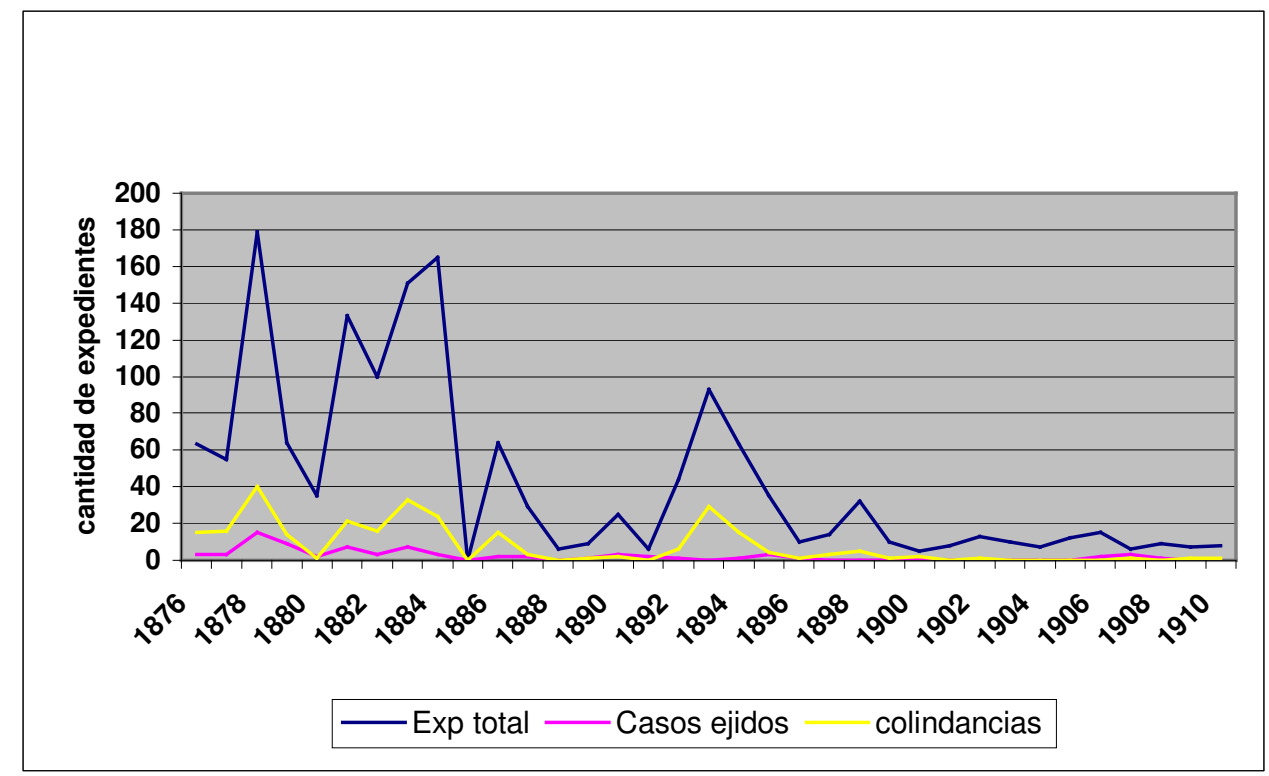

Fuente: Juzgado de Distrito. Ramo Civil. Chiapas.

Si el conjunto documental lo transformamos en cantidades simples podremos alcanzar una comprensión más clara de cuántos casos hablamos a continuación:

Denuncios relativos a tierras ejidales y sus colindancias, en relación con el total de denuncios presentados al JD-Chiapas, 1876-1910

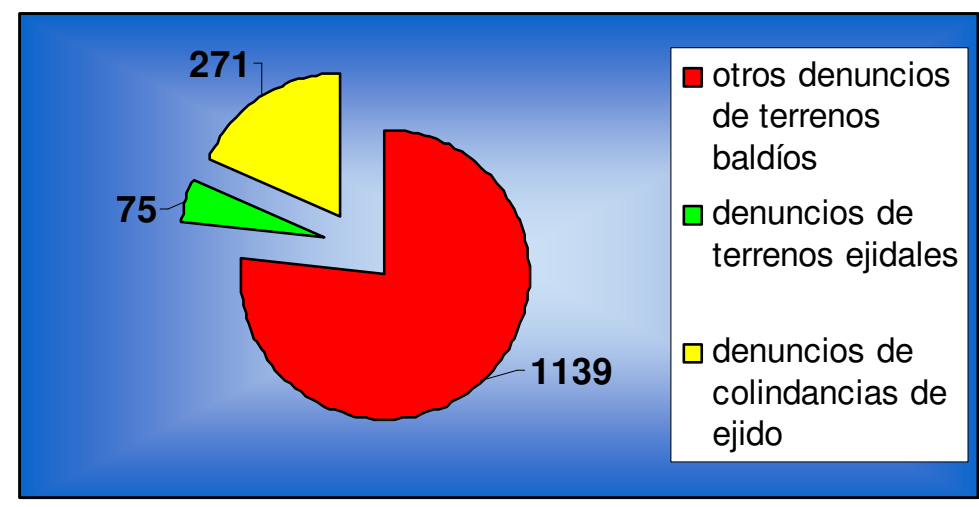

Fuente: Juzgado de Distrito. Ramo Civil. Chiapas.

En esta gráfica se aprecia que los denuncios más probables en donde podía darse un peligro inminente para la paz pública del estado —los denuncios de tierras consideradas 
colectivas- solo alcanzan 5\% del total. Si incluimos en esta categoría los denuncios de colindancias con tierras colectivas se llega a $23.2 \%$ de los expedientes revisados. La siguiente exploración de los datos presenta las características que son comunes a los dos tipos de denuncios de las tierras colectivas, también considera la solución o sentencia que obtuvieron y especifica, en donde resulta necesario, las diferencias entre ambas.

Como representante del Poder Judicial Federal, le correspondía al juez de distrito dirimir y solucionar los conflictos que surgieran de los denuncios de terrenos considerados por los pueblos como terrenos comunales o ejidos, y por los denunciantes como terrenos baldíos, de ahí que se abriera un juicio de oposición.

Del conjunto de casos detectados podemos hacer una primera diferenciación en tres categorías. Los que no logran la titulación: 209 de los 346 expedientes (60\%); los que sí la logran: 91 casos (26.3\%), y los denuncios cuyos expedientes resultaron sin sentencia, incompletos o parcialmente destruidos: 35 casos $(10 \%) .{ }^{17}$

La primera categoría incluye:

- Denuncios que no lograron su adjudicación y titulación

- por desistimiento de una de las partes;

- por declarar el agrimensor que el terreno baldío denunciado no existe;

- por no pagar el denunciante al agrimensor;

- por acuerdo armonioso entre las partes.

Se añaden los que fueron resueltos por alguna sentencia del JD

- mediante declaración de "No ha lugar" o declaración de desistimiento remitida por: 


\section{- $\quad$ el Juzgado de Distrito;}

- $\quad$ el Juzgado de Circuito;

- $\quad$ la Secretaría de Fomento;

- $\quad$ el presidente de la República.

A la segunda categoría pertenecen

- casos que realizaron correctamente todo el procedimiento normal de un denuncio de tierras baldías; se incluyen casos de juicios de oposición que terminaron en la titulación.

La tercera categoría se compone de

- casos cuyos trámites administrativos o seguimientos judiciales fueron interrumpidos sin aclaración, quedaron sin sentencia o con la documentación incompleta. 
209 denuncios de tierras ejidales o colindancias que no lograron su titulación, 1876-1910

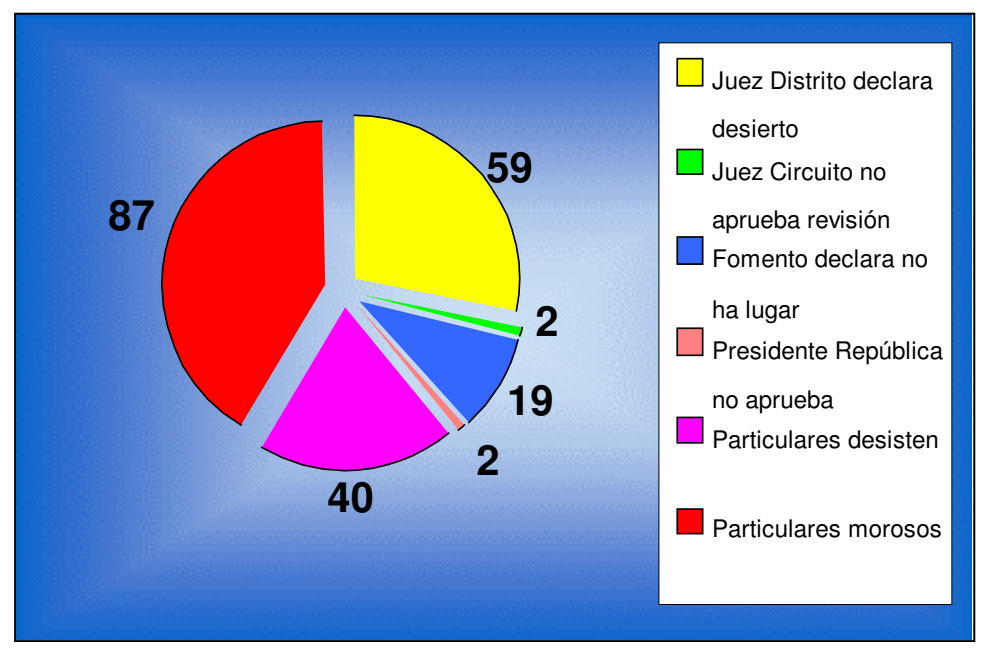

Fuente: Juzgado de Distrito. Ramo Civil. Chiapas.

La duración de los trámites de denuncio o juicios de oposición era variable. Fueron pocos los que se resolvieron en menos de un año, prevalecían los casos cuya duración oscilaba entre cinco y diez años con algunos que tardaron de quince a veinte años, lo que significaba, especialmente en el tema de los juicios, un largo tiempo de zozobra para las partes en pugna, gastos de abogados, búsqueda, copiado y certificación de documentos de propiedad, ${ }^{18}$ viajes del síndico o apoderado municipal realizados con el objetivo de presentarse frente a las autoridades. De manera especial, para los ayuntamientos rurales sin ingresos propios de consideración, los gastos que un pleito judicial de larga duración implicaba podían convertirse en un factor decisivo para la disposición de arreglarse armoniosamente o no con el denunciante. ${ }^{19}$

Respecto a la mayoría de los casos que no terminaron en titulación, por las razones arriba indicadas, hace falta información para argumentar las causas verdaderas, porque no presentaron mayor acumulación documental y fueron declarados casos cerrados por 
"desistimiento" por el juez de distrito, entonces solo puede especularse sobre las verdaderas razones del desistimiento o de la morosidad de parte del denunciante. Únicamente en algunos pocos casos de desistimiento se mencionan las razones, entre las que cuentan el fallecimiento del interesado; falta de fondos para pagar al agrimensor; que éste no se presentó a la medida del terreno; por haberse cambiado de residencia el denunciante; por el reconocimiento de estar adjudicadas las tierras denunciadas, y porque "no conviene a sus intereses seguir adelante con el denuncio" ${ }^{20}$. Los juicios de oposición en los que fue registrado el uso de violencia — tres casos- permiten conocer, por las denuncias de parte del interesado o del agrimensor, que uno de los métodos aplicados por parte de las comunidades para evitar el seguimiento del denuncio o de la medida era la amenaza contra la integridad física del denunciante. ${ }^{21}$

\section{LA DISPUTA JURÍDICA}

La expedición de la ley de desamortización de 25 de junio de $1856,{ }^{22}$ que ordenaba la privatización de las propiedades colectivas de las comunidades, y la nueva Constitución de febrero de 1857, crearon la base argumentativa sobre la cual se desarrollaron en adelante los juicios que involucraban por un lado a los denunciantes de supuestos terrenos baldíos y por el otro a los ayuntamientos de municipios indígenas y/o a la colectividad de la población en su función de derechohabiente del ejido.

Las disputas jurídicas giraron básicamente alrededor de las siguientes dos cuestiones: ¿el ayuntamiento, a pesar de las leyes de desamortización, seguía teniendo personalidad jurídica para representar y defender los intereses colectivos relacionados con las tierras del 
pueblo? ¿Los denuncios presentados por particulares podían o no abarcar terrenos originalmente propiedad colectiva de las comunidades? Es precisamente la posición que asumen los jueces de distrito frente a estos dos puntos y su efecto sobre las sentencias dictadas, los que pueden servir de parámetro para poder argumentar con mayor certeza respecto a las repercusiones que han tenido las Leyes de Reforma sobre la propiedad colectiva. Es en estas sentencias donde se aprecia la posición asumida por la justicia federal en el estado en los momentos en que la ley y los intereses de las comunidades se enfrentaron.

Para el grupo de denuncios aquí considerado, resulta revelador hacer una diferenciación entre los que involucraban tierras colindantes a ejidos y posiblemente ocupadas en forma irregular por los vecinos de la comunidad, y los que se referían a tierras que los integrantes de la comunidad consideraban como colectivas desde tiempos inmemoriales, amojonadas y posiblemente amparadas por título. De los 346 casos aquí investigados, 271 se refieren a denuncios de colindancias, mientras 75 tienen como objeto de la controversia tierras consideradas de propiedad colectiva. Puede suponerse que los 75 casos significaban desde la probabilidad un mayor riesgo de provocar posibles resistencias violentas, que podrían traer hasta una movilización como la que se dio en la llamada "Guerra de Castas" de 18671871 en Los Altos de Chiapas.

El análisis de los resultados obtenidos en ambos tipos de denuncios revela una estricta aplicación de las leyes vigentes en la materia por parte de los jueces en su esfuerzo por evitar o solucionar conflictos. Frente a un total de denuncios titulados en casos de colindancias con ejidos de $29 \%$, esta tasa se redujo a $16 \%$ en casos de denuncios sobre 
tierras colectivas. A la inversa, significa que del total de 75 denuncios de esta última categoría, 63 terminaron de forma negativa para los denunciantes. Entre ellos destaca que 23 o 31\% nunca llegó a sentencia y tampoco anotó algún desistimiento. Los casos quedaron abiertos durante muchos años, durante los cuales conservaron el statu quo anterior, lo que en realidad significaba, en los casos aquí analizados, favorecer a las comunidades, ya que seguían utilizando los terrenos. ${ }^{23}$ El resto, que equivale a $53 \%$ de los denuncios de esta categoría, fue declarado como desistido o los denunciantes renunciaron por iniciativa propia.

\section{LOS JUICIOS DE OPOSICIÓN}

En ambas categorías de denuncios, varios de ellos desembocaron en juicios de oposición por la resistencia que presentaron las comunidades y los ayuntamientos frente al denunciante particular. En relación con los denuncios de colindancias, las comunidades iniciaron diez juicios, y para los denuncios de tierras colectivas veintisiete. Los treinta y siete juicios en el lapso de treinta años equivalen a $10.7 \%$ del total de los casos en las dos categorías.

Los argumentos justificadores, presentados en el juicio por los denunciantes o sus apoderados, eran bastante reiterativos, insistían en que las Leyes de Reforma no solo obligaban a repartir los ejidos, sino que las mismas leyes permitían a los particulares denunciarlos ${ }^{24}$ mientras que a la vez negaban la personalidad jurídica de los ayuntamientos para poder defender las tierras de la ya extinguida propiedad colectiva. Los denunciantes partían del supuesto de que, desde la promulgación de las Leyes de Reforma, la propiedad 
colectiva de tierras en las comunidades había dejado de existir. Ningún juez se oponía al mandato de las leyes en cuestión, que exigían la desamortización de las tierras colectivas de las comunidades, pero la segunda parte del argumento, es decir, que los particulares estaban capacitados para denunciar las tierras referidas, fue rechazada con regularidad por los promotores fiscales y jueces de distrito. La razón para tal rechazo era que, de acuerdo con las leyes vigentes, el reparto debía realizarse solo y exclusivamente entre los integrantes del ejido, sin reconocer derecho alguno sobre estas tierras a particulares ajenos a éste.

El segundo argumento sobre la personalidad jurídica del ayuntamiento llevó incluso a la Corte Suprema de la nación a largas y encontradas discusiones, sin lograr una opinión uniforme. Todos los magistrados se percataron del peligro que corrían las tierras colectivas de las comunidades si no se encontraba alguna solución para protegerlas de las ambiciones ajenas mientras se realizaban la remedida y el fraccionamiento, pero las propuestas diferían. Unos mantenían que los ayuntamientos, en vez de contar con personalidad jurídica para representar los intereses del común del pueblo, deberían ser considerados y reconocidos como representantes o apoderados de una sociedad agrícola — conforme al Código Civil—, la que unía al conjunto de los antiguos integrantes del ejido, buscando así evitar que las tierras de las comunidades quedaran sin protección y al alcance de interesados ajenos.

Otros magistrados optaron por una solución intermedia —aparentemente eran más sensibles con la realidad vivida por las comunidades y reconocían que con frecuencia el proceso del reparto de las tierras colectivas iba muy lento e incluso tardaba años o décadas en realizarse, consecuencia de ello es que en un sinfín de casos, aun décadas después, no se había ni siquiera iniciado el proceso de remedida y fraccionamiento- Defendieron la 
obligación estipulada por la Constitución de medir y fraccionar las tierras colectivas, pero a la vez argumentaban que, mientras esto pasara, los ayuntamientos no contrariarían la Carta Magna haciéndose "cargo de la administración de esos terrenos solo para el efecto de repartirlos y venderlos"; así reafirmaban su personalidad jurídica para poder defender los terrenos contra denuncios malintencionados. ${ }^{25}$

La lentitud del reparto efectivo de las tierras colectivas pertenecientes a las comunidades en Chiapas, frente al marcado interés de varios denunciantes particulares de adquirir estas tierras en propiedad, provocó frecuentes posicionamientos de los promotores fiscales, de los jueces de distrito y de los jueces de circuito en favor de las comunidades y de sus representantes: los ayuntamientos. Durante el tiempo revisado (1876-1910), incluidos los años desde 1856 a 1876, no existe prueba en los expedientes de que el Juzgado de Distrito haya desconocido o puesto en duda la personalidad jurídica de los ayuntamientos o de sus apoderados. Hasta 1910, los que promovían los juicios de oposición eran los síndicos o los respectivos apoderados del ayuntamiento. ${ }^{26}$ Esta disposición favorable a los intereses de las comunidades por parte de los jueces de distrito llegó a tal grado que hasta en el denuncio de las tierras del ejido de Santa Catarina Huitiupán, municipio a punto de desaparecer por contar con solo diecisiete familias y el cual no mandó ningún representante en su defensa por carecer de autoridades formales. El juez de distrito declaró sin lugar el denuncio por tratarse de tierras destinadas a un uso público, "como es la congregación de familias en la forma de un pueblo legalmente reconocido y establecido, que se sirve de él para explotarlo y llenar sus necesidades" ${ }^{27}$. 
Es difícil comprobar que no haya habido presiones por parte de los grupos afines a la clase social del juez o por parte del gobierno estatal, pero el hecho de que se encontró entre los juicios de oposición, sentenciados por los jueces, varios en contra de miembros de la oligarquía del estado y hasta de personas cercanas al gobierno federal, ${ }^{28}$ hace suponer que el elevado rango social de uno de los contendientes no fue un factor decisivo para que la sentencia le resultara favorable. ${ }^{29}$

En un breve análisis de los juicios de oposición contra denuncios de tierras colectivas, se observa una clara tendencia en la actuación y en las sentencias dictadas por el JD que favorece a las comunidades. Mientras que de los 271 casos de denuncios de colindancias con ejidos el JD solo abrió 10 juicios de oposición, lo que equivale a menos de 4\%; en cambio se encuentran 27 juicios entre los 75 casos de denuncios de tierras consideradas colectivas, ${ }^{30}$ lo que supone más de $20 \%$. Tal hecho subraya el mayor grado de potencial conflictivo de estos últimos casos. Pero, números aparte, resulta ilustrativo conocer cómo finalizaron tales juicios: solo dos de ellos terminaron con titulación en favor de los denunciantes; dos finalizaron en arreglos armoniosos con la comunidad respecto del trazo de la línea de colindancia; cuatro fallos confirmaron el mejor derecho de las comunidades; otros cuatro concluyeron al ser declarado el desistimiento del interesado; mientras el resto —quince juicios- nunca llegaron a sentenciarse y el expediente respectivo quedó inconcluso por razones desconocidas.

Lo que aquí se da a entender es que no es solo un aumento considerable de juicios de oposición cuando los denuncios trataban de tierras aparentemente colectivas, sino también una creciente disposición por parte de las comunidades y ayuntamientos a utilizar los 
vericuetos jurídicos en los casos de una posible afectación de su control sobre las tierras del común. Únicamente se registraron dos expedientes en los que, antes de llegar a juicio de oposición, los comuneros resistieron al denuncio con las armas en mano. Este hecho confirma que existía el conocimiento por parte de las comunidades de las instancias jurídicas y de cómo utilizarlas para su beneficio, también demuestra un cierto grado de confianza, al dar preferencia a la instancia del Juzgado de Distrito con la que lograr así una dilatación considerable del caso o por creer en la justicia propiamente impartida por él. El hecho de que solo dos denuncios fueron dictaminados en favor de los denunciantes particulares muestra un proceder del Juzgado de Distrito apegado a la Constitución y a las leyes que definían el fraccionamiento de las tierras colectivas única y exclusivamente entre miembros de la comunidad.

\section{FACTORES NO JURÍDICOS Y SU INFLUENCIA SOBRE EL DESENLACE DE LOS DENUNCIOS}

Durante estos años, y además de mantener los jueces una sola interpretación de las Leyes de Reforma, de la Constitución de 1857, y de las leyes subsiguientes, favorable a las comunidades y sus tierras colectivas, existían factores de carácter técnico-administrativo en los que el Juzgado de Distrito tuvo participación y que contribuyeron a que una cantidad considerable de denuncios se resolvieran, ya fuera por declarar el desistimiento el propio denunciante, o por declararlo el juez de distrito, argumentando morosidad.

Para poder valorar mejor la labor desarrollada por el Juzgado de Distrito de Chiapas, es preciso mencionar que su personal estaba limitado a tres personas: un juez, un suplente y un 
secretario. A ellos les tocó dar seguimiento y resolver centenares de casos cada año, no solo de denuncios de tierras, sino igual o mayor cantidad de casos del ramo penal y de juicios de amparo; su único apoyo externo fue el de un promotor fiscal.

Esta situación y la escasa infraestructura de comunicaciones en Chiapas, que consistía exclusivamente en caminos de herradura y veredas, intransitables en temporada de lluvias, contribuyeron en buena medida a que los denuncios de tierras baldías se volvieran tediosos y prolongados. Cuando después de muchos meses, en algunos casos años, el agrimensor por fin iniciaba el deslinde y las medidas, ya algunos de los denunciantes habían muerto y varios cambiado su lugar de residencia. Otros más, decepcionados por haber hecho gastos en balde para las certificaciones, el envío de los documentos o el nombramiento de apoderado, y perdida cualquier esperanza de obtener una resolución favorable, habían renunciado al denuncio o habían vendido en el intervalo su derecho a terceros, provocando así el reinicio de trámites para el reconocimiento judicial del nuevo derechohabiente.

La lentitud de la comunicación entre el denunciante, el juzgado y los agrimensores, y la consecuente pérdida de interés de parte de los primeros, dieron lugar a que ellos abandonaran o que los jueces los declararan morosos, decretando su desistimiento.

Un efecto similar tuvo el reducido número de agrimensores, del cual el juez de distrito se vio obligado a seleccionar y nombrar los responsables para el deslinde y la medida de los terrenos denunciados. La escasez de personal profesional, frente a un número considerable de denuncios, provocó sobrecarga de trabajo y renuncias después de años de trámite, obligando al JD a nombrar a otro en las mismas condiciones. La dificultad para trasladarse 
a las localidades, la ausencia absoluta de seguridad, las inclemencias del tiempo, hicieron del trabajo del agrimensor una actividad que ponía en riesgo su integridad física. Las amenazas de muerte por parte de las comunidades y los particulares, junto con el diario riesgo para la salud, les indujeron a actuar con mucha cautela; varios de ellos prefirieron renunciar a los encargos antes de exponerse a posibles hechos violentos. Una situación así podía retrasar las medidas indefinidamente.

Otros agrimensores con mayor sensibilidad por la situación y las necesidades de las comunidades, también contribuyeron a que los denunciantes finalmente desistieran. Sin esgrimir esfuerzos ni argumentos, ellos hicieron todo lo posible, a pesar de su defectuosa elaboración por respetar los planos antiguos y los mojones indicados y reconocidos por los vecinos del pueblo, en determinados casos también persuadieron al denunciante de que retirara o rectificara su denuncio para evitar posibles consecuencias funestas. En ciertas situaciones llegaron incluso a negarse a realizar medidas de tierras de particulares sobre terrenos baldíos en simple posesión de vecinos de una comunidad, respetándolos como si fueran parte de las tierras comunales reconocidas. ${ }^{31}$ Otros en cambio no dudaron, cuando se dio resistencia pacifica o violenta por parte de los ayuntamientos, en solicitar el apoyo de la fuerza pública para intimidar e incluso encarcelar a las autoridades y vecinos renuentes, para poder terminar, con la protección militar, la medida ordenada por el juez de distrito. Los resultados de tales actuaciones provocaban nuevas amenazas contra agrimensores y denunciantes que incitaban a una aún mayor antipatía de la comunidad contra el denunciante, lo que llevó a éste a desistir de su propósito en varias ocasiones. 
Otra consecuencia negativa de la notoria escasez de agrimensores era que el juez de distrito, al extender los nombramientos, tuviera que recurrir a agrimensores menos experimentados o a simples prácticos, con lamentables consecuencias para las partes. La impericia de los prácticos resultó en planos incompletos, algunos realizados sin salir del gabinete, con graves omisiones respecto a colindancias y ubicaciones precisas de los mojones. Estos planos ficticios fueron acompañados por informes rudimentarios cuyas imprecisiones, si no fueron detectadas por el propio juez o el promotor fiscal, no pasaron la revisión de la Secretaría de Fomento que declaraba la improcedencia del denuncio. Cuando esto sucedía ya habían transcurrido varios años desde el denuncio original.

Se dieron casos de denuncios que, después de haber pasado de forma correcta por todos los trámites y contando incluso con la aprobación de la comunidad colindante, fueron rechazados directamente por el presidente Porfirio Díaz. ${ }^{32}$

Varios otros se resolvieron porque los interesados cambiaron de parecer o al presentarse el agrimensor se vieron en la necesidad de desistir del denuncio por falta de dinero para pagar sus servicios. Entonces, el juez de distrito, después de varios exhortos, declaraba la morosidad de los denunciantes y la pérdida del derecho de reclamar de nueva cuenta el mismo terreno. 


\section{LAS COMPAÑÍAS DESLINDADORAS Y LAS TIERRAS COLECTIVAS}

Las compañías deslindadoras se caracterizaban por su doble papel de agentes del gobierno en la detección y persecución de ocultadores de mala fe de los terrenos baldíos y el de empresas con intereses especulativos en el mercado de tierras. ${ }^{33}$

La deficiente titulación de los terrenos en propiedad y la feliz costumbre de los chiapanecos de ocupar terrenos baldíos sin procurar su regularización hizo que, en el momento de comenzar los deslindes, la mayor parte de las propiedades y posesiones fueran legalmente cuestionables ${ }^{34}$ La imprecisión de los títulos expuso a los propietarios y comunidades al enorme riesgo de perder gran parte de lo que consideraban suyo por justo derecho y por antigüedad. Esta situación obviamente iba a causar problemas en el momento en que el gobierno federal decidiera imponer la ley, y ofreciera al propietario dos alternativas: legalizar su posesión de excedencias y someterla a la fiscalización o ser considerado defraudador de los intereses financieros de la nación; las consecuencias, por lo regular, significaban la pérdida del terreno sin compensación.

En el archivo del Juzgado de Distrito de Chiapas, fueron detectados alrededor de 1,500 casos de personas que una vez llevado a cabo el denuncio ocuparon y aprovecharon el terreno en cuestión sin ocuparse de seguir los trámites. ${ }^{35}$ Estos casos son los que llegaron al conocimiento del Juzgado; otro tanto, que es difícil calcular, simplemente ocupaba tierras sin hacer solicitud ninguna, confiado en la distancia entre las apartadas zonas del estado y el Juzgado. ${ }^{36}$ 
Este dramático ambiente de inseguridad jurídica de la propiedad rural en Chiapas prevalecía en el momento de la llegada de las compañías deslindadoras. Los descuidos anteriores que habían mantenido a la propiedad en un estado de ilegalidad respecto de las leyes nacionales, habían creado un suelo potencialmente fértil para futuros choques entre los intereses de la nación, representados por las compañías deslindadoras, y los propietarios o poseedores. En su función de agentes del gobierno, las compañías debían perseguir todos los casos de ocultación de terrenos baldíos, promoviendo su regularización o, en caso negativo, recuperando los terrenos en cuestión para la nación. Si hubieran cumplido al pie de la letra con este encargo, no solo se hubiera enrarecido enormemente el clima social en el estado, mediante resistencias violentas y duraderas, tampoco las compañías hubieran podido terminar los deslindes en tiempo y forma por las múltiples rebeldías, con lo que podrían perder los derechos y ventajas inherentes a la concesión de deslinde. El espíritu empresarial de las compañías obligó a buscar una estrategia que les permitiera poner a salvo intereses en situaciones desfavorables como en el caso de Chiapas.

Luis Hüller y Cía. y compañías sucesoras, concesionarias de los deslindes, optaron por un camino al margen de la ley. Las compañías, a pesar de tener conocimiento de la ilegalidad de un supuesto título o de lo injustificado de un reclamo sobre ciertas tierras, prefirieron reconocer tácitamente los supuestos derechos del reclamante, evitando de esta manera un sinfín de conflictos judiciales y resistencias que podrían haber retrasado eternamente la conclusión de los deslindes y con ello la titulación de las tierras. Actuar con flexibilidad, para evitar juicios y pleitos administrativos, les posibilitaba concentrarse en lo que 
consideraban ser el propósito principal de su negocio: poder realizar lo más pronto posible la comercialización de los terrenos baldíos indisputables.

En la aplicación de esta política, que les trajo fuertes críticas del gobierno federal, las compañías no diferenciaban entre poseedores particulares o colectivos de terrenos baldíos. Es incluso posible que, tratándose de una posesión de una comunidad, los ingenieros agrimensores hayan tenido aun mayor cuidado, si se toma en cuenta los riesgos que corrían al exponerse a la furia de una comunidad en defensa de sus derechos. ${ }^{37}$

Los registros de las propiedades acreditadas y respetadas en los deslindes, conservados en el archivo del Juzgado de Distrito, demuestran que, con pocas excepciones, las compañías respetaron las extensiones de tierras colectivas amparadas por título, incluso las excedencias que el pueblo, por antigüedad, reclamaba en esos momentos como parte del ejido.

Se registraron únicamente tres casos, en los cuales la Compañía, al medir los ejidos, parece haber respetado exclusivamente los terrenos colectivos amparados por títulos y en los que el desconocimiento de las excedencias del ejido resultó en un conflicto posterior. Es importante subrayar que en ninguno de los conflictos hubo uso de violencia de parte de la compañía o de las autoridades, como tampoco de parte de los reclamantes.

Uno de éstos, en el municipio de Escuintla, está ubicado en la zona del Soconusco, los otros dos en la región de Motozintla. En el primero las tierras fueron medidas en 1886, sin que se anotara alguna inconformidad de la comunidad porque se le hubiera invadido terrenos. El 
expediente de deslinde incluye un acta firmada por las autoridades del pueblo donde se declara que habían sido respetados los mojones que ellos mismos indicaron a los ingenieros y que estaban conformes con los resultados del deslinde. Entre los predios respetados aparece el ejido del pueblo con 38 caballerías o 1,596 hectáreas. ${ }^{38}$ Durante las más de dos décadas posteriores el pueblo no cuestionó la medida; pero veintitrés años después de haber terminado el deslinde, en 1909, las autoridades del pueblo denunciaron ante la Secretaría de Fomento que Land Company of Chiapas (LCCH), empresa deslindadora, pretendía venderles terrenos en posesión de la comunidad. El origen de la queja fue que la población del pueblo había crecido, ocupando ilegalmente terrenos de la compañía que aún no había vendido. Al darse cuenta la deslindadora les exigió que compraran los terrenos a un precio preferente, a lo que rehusaron las autoridades con el argumento de que los terrenos eran posesión antigua del pueblo. El caso llegó a la Secretaría de Fomento, esta dictaminó que sí habían sido respetados los terrenos de la comunidad y que los terrenos en litigio eran propiedad legítima de la compañía.

En el otro caso de Motozintla y Mazapa, ubicados en la Sierra Madre al norte del Soconusco, las desavenencias nacieron cuando en 1898, al medir los terrenos, los pobladores insistieron en que la compañía les respetara 300 caballerías -12,600 hectáreas - a cada pueblo, cuando sus títulos amparaban apenas 20 caballerías —840 hectáreas- cada uno. La compañía les ofreció ceder gratuitamente 23 caballerías adicionales a las 20 y prometió vender cualquier otro terreno colindante de interés para los pueblos a un precio módico. El mismo año 1898 la compañía midió los ejidos de Mazatán, y en 1900 los de Motozintla; al manifestar su conformidad, recibieron los títulos en 1913. 
Otros trece casos que surgieron en la misma zona de Motozintla entre 1907 y 1909 tuvieron su origen en la migración guatemalteca. Esta región había sido integrada al estado apenas en 1882 como parte de los acuerdos sobre límites entre México y Guatemala. En este convenio, México se había obligado a respetar las posesiones establecidas y ceder terrenos a los que los pidieran. Sin haber cumplido con el registro de las propiedades, el gobierno cedió estos terrenos como parte de las zonas deslindadas en 1886 a una compañía deslindadora. En años inmediatamente posteriores, la región recibió fuertes migraciones de guatemaltecos, quienes formaron nuevo pueblos sobre terrenos ya titulados a esta compañía deslindadora. Sin documento alguno, ni con el derecho de posesión antigua, estos asentamientos exigían tierras para el fundo de su pueblo y para el ejido. Con el fin de evitar mayores desavenencias, la compañía, en el año 1907, hizo promesa de venta, a precios rebajados, de los terrenos deseados por los migrantes. La falta de dinero para pagar a la compañía provocó que estos casos se volvieran tediosos y conflictivos. Cuando la prensa y el Congreso local retomaron los casos, los utilizaron como pruebas para supuestas usurpaciones de tierras de comunidad de parte de la compañía. Fueron precisamente estos acontecimientos los que retomaron algunos investigadores, mismos que, sin haber investigado el origen del conflicto, los manejaron como prueba fehaciente de la imagen de una compañía extranjera explotadora de los terrenos baldíos y cuya acción afectaba los derechos de las comunidades indefensas. ${ }^{39}$ Que no habían existido ni los pueblos reclamantes, ni los supuestos ejidos ni las posesiones reclamadas, no era noticia, tampoco lo era que, a pesar de estos antecedentes, después todos los casos fueran resueltos por la compañía. En junio de 1913, luego de un arreglo general con el gobierno, la compañía cedió y midió 40,434 hectáreas para satisfacer las demandas pendientes y cerrar así los casos un mes después, en julio de 1913. 
En el resto del estado, no hubo roces significativos con propiedades colectivas que no fueran resueltos casi de inmediato y de común acuerdo. Por los deficientes títulos aparecieron desacuerdos durante los deslindes sobre límites, pero estos quedaron resueltos armoniosamente. En los últimos años de la presencia de LCCH en Chiapas, entre 1912 y 1916, hubo varias quejas por el cobro de arrendamientos que fueron considerados exagerados. Una investigación del agente de la Dirección agraria del gobierno federal dictaminó que varias de las querellas habían sido ficticias y que en otras la suma cobrada no rebasaba lo acostumbrado en la zona. ${ }^{40}$

Es sorprendente que a pesar del enorme peligro de provocar conflictos y pleitos jurídicos, los deslindes en Chiapas se realizaron en un clima de relativa tranquilidad. No solo los poseedores, incluidas las comunidades, buscaron el arreglo con el gobierno para regularizar sus posesiones, también la Land Company tenía una notoria actitud de respetar las posesiones originales, aunque ilegales, para no enrarecer el clima en que se realizaban los deslindes. El hecho de que la compañía incluyera entre los predios respetados a los ejidos les dio a éstos cierta protección legal. Muchos de ellos no contaban con títulos o los habían extraviado, sustituyendo la medida realizada por la deslindadora, por lo pronto, al título. En casi todos los casos los ingenieros respetaron los mojones reales o supuestos que la comunidad reclamaba como suyos.

Cuando el juez de distrito suspendió todos los denuncios de terrenos baldíos, demasías y excedencias, a partir del momento de iniciar la compañía los deslindes, paralizó igualmente los denuncios sobre terrenos de los ejidos o sus excedencias. De esta manera las 
comunidades quedaron protegidas contra las aspiraciones de finqueros colindantes y pudieron mantener, durante ocho años (1886-1894), el anterior statu quo de sus terrenos. Varios de estos denuncios pendientes, una vez levantada la suspensión, no fueron reactivados por los interesados; así muchas de las posesiones o propiedades de las comunidades quedaron intactas.

\section{CONCLUSIONES}

El difícil acceso a la documentación que tiene como referencia la cuestión de la tierra durante el siglo XIX, y por ende el desconocimiento preciso de los acontecimientos, llevó a los historiadores a dibujar el clásico cuadro de las comunidades indígenas impotentes, que perdieron sus propiedades colectivas ante las manos de un grupo de hacendados, clérigos e inversionistas-deslindadores en alianza con funcionarios del gobierno y de la justicia.

Los resultados obtenidos de la revisión de los expedientes del Ramo Civil del Juzgado de Distrito, correspondientes a los años del Porfiriato y referentes a denuncios de tierras baldías presentados ante el juez y su efecto sobre las tierras colectivas de las comunidades, deben ser considerados preliminares en el entendido de que será necesario corroborarlos con los datos resguardados en los archivos del Poder Judicial estatal y de los municipios, que también conservan documentación de los litigios sobre tierras colectivas.

Hasta ahora solo se puede aseverar que la información detectada en el archivo histórico del Juzgado de Distrito contradice en forma diametral la historiografía chiapaneca reciente sobre el tema de la pérdida de las tierras colectivas durante el último cuarto del siglo XIX y 
primera década del siglo $\mathrm{XX}$, lo que invita a realizar una revisión exhaustiva de los archivos complementarios. El conjunto de datos localizados en el Juzgado de Distrito se opone a la ya clásica hipótesis de una severa usurpación de las tierras colectivas por parte de un determinado grupo oligárquico, y evidencia en cambio nuevos aspectos que deben tomarse en cuenta para las siguientes investigaciones. Los jueces de distrito y los promotores fiscales actuaron con un sorprendente grado de responsabilidad social y sus fallos favorecieron en la mayoría de los casos a las comunidades, respaldando sus derechos. Destaca que los enfrentamientos judiciales — juicios de oposición— sobre denuncios de tierras, supuesta o verdaderamente colectivas, fueran relativamente bajos, y que la tasa de fallos favorables a los denunciantes y en contra de los intereses de las comunidades fuese todavía mucho más reducida; hechos que refutan para el caso de Chiapas tanto la supuesta parcialidad de los jueces de distrito con los hacendados, como la sugerida usurpación de la mayor parte de las tierras de comunidad, por finqueros y compañías deslindadoras, como han mantenido los autores mencionados al inicio de este escrito. ${ }^{41}$

Las sentencias pronunciadas por los jueces de distrito revierten la acusación de parcialidad de la justicia en un sorprendente y constante apego de los promotores fiscales, jueces de distrito y de circuito a la legislación vigente sobre desamortización de los ejidos; la poca claridad de los textos legales les permitió dictar fallos o iniciar procedimientos judiciales que a la larga favorecieron a los opositores indígenas.

Excepto en un número muy reducido, la acción de las compañías deslindadoras en el estado de Chiapas no provocó conflictos con las comunidades y los que surgieron fueron resueltos con arreglo entre las partes. El interés empresarial de las compañías deslindadoras era 
móvil eficaz para evitar posibles conflictos y desavenencias con los poseedores de terrenos baldíos, lo que llevó a los ingenieros a registrar y respetar muchas posesiones de facto que no eran más que usurpaciones.

Será necesario matizar la tradicional visión de los pueblos indígenas desentendidos del mundo ladino que los rodea, viviendo expuestos y sometidos a las múltiples arbitrariedades que los mantienen en una sujeción total. En los expedientes del Juzgado de Distrito aparecen los ayuntamientos indígenas como actores concientes de sus derechos y perseverantes en su disposición por defenderlos aun en los tribunales de los ladinos. La práctica de recurrir al camino judicial, aunque fuera con el apoyo de un apoderado, refleja el conocimiento de las instancias legales e implica un grado de aceptación del sistema de leyes del Estado mexicano, que les permitía tener la confianza en poder defender sus intereses. Habrá que corroborar en el futuro esta imagen de las comunidades indígenas que no temían oponerse al grupo en el poder mediante las armas y los hechos, pero con marcada preferencia por el sistema judicial, como defensores activos y efectivos de sus intereses colectivos y como una manifestación política — como tantas otras- no reconocida hasta hoy por la historiografía sobre el Chiapas decimonónico. 


\section{BIBLIOGRAFÍA}

Fuentes Primarias

Archivo Histórico de la Casa de la Cultura Jurídica de Chiapas, Tuxtla Gutiérrez.

Diversos expedientes del Juzgado de Distrito, Ramo Civil, correspondientes a los años 1876-1910.

Archivo de Terrenos Nacionales (SRA/ATN) de la Secretaría de la Reforma Agraria, Sección Chiapas, México, D.F.

Impresos, Periódicos

Anónimo, 1909, Amparo promovido en el Estado de Chiapas por los Sres. Ing. Carlos Z. Flores y Martín Morales contra una sentencia de la 2a Sala del Supremo Tribunal de dicho Estado, que declaró indivisa la Finca Chempil y absolvió a los demandados en juicio de reivindicación de la obligación de desocupar el inmueble. México.

El Espíritu del Siglo, tomo IV, núm. 86, 4.4.1868. Tuxtla Gutiérrez, Chiapas.

Bibliografía citada

Benjamín, Thomas Louis, 1990, El camino a Leviatán. Chiapas y el Estado mexicano, 1891-1947. CONACULTA, México.

De la Peña, Moisés T., 1954, Chiapas económico, 4 tomos. Tuxtla Gutiérrez, México.

De la Torre, Juan, 1892, Legislación de terrenos baldíos. Imprenta del Gobierno, Morelia.

Díaz Leal, José, 1878, Legislación y Guía de Terrenos Baldíos. Imprenta de Francisco Díaz de León, México.

Dublán, Manuel y José María Lozano, 1894, Legislación mexicana o Colección completa de las disposiciones legislativos, vol. XXIV. México.

Fabila, Manuel, 1990, Cinco siglos de legislación agraria (1493-1940), 2. edición. SRACEHAM, México.

Favre, Henri, 1984, Cambio y continuidad entre los mayas de México. Contribución al estudio de la situación colonial en América Latina, 2. ${ }^{a}$ edición, Colección INI, núm. 69. México, D.F.

Ferrer, Manuel y María Bono, 1998, Pueblos indígenas y Estado nacional en México en el siglo XIX, Instituto de Investigaciones Jurídicas, Serie C: Estudios Históricos, núm. 79. UNAM, México, D.F. 
Fujigaki Cruz, Esperanza, 1988, "Las Rebeliones campesinas en el Porfiriato". En Historia de la cuestión agraria mexicana, La tierra y el poder, 1800-1910, coordinado por Enrique Semo, tomo 2. Siglo XXI, México.

García de León, Antonio, 1985, Resistencia y Utopía. Memorial de agravios y crónica de revueltas y profecías acaecidas en la provincia de Chiapas durante los últimos quinientos años de su historia, dos tomos. Ediciones Era, México. (Colección Problemas de México.)

Gobierno del Estado, 1878, Colección de leyes agrarias y demás disposiciones que se han emitido con relación al Ramo de Tierras. Mandadas a reimprimir de orden del superior gobierno del Estado. Imprenta Joaquín Armendáriz, s/l.

González de Cossío, Francisco, 1981, Historia de la tenencia y explotación del campo desde la época precortesiana hasta las leyes del 6 de enero de 1915, tomo I. SRACEHAM, México, D.F.

González Navarro, Moisés, 1985, "La vida social". En Historia Moderna de México. El Porfiriato, coordinado por Daniel Cosío Villegas, 4. a edición. México, Buenos Aires.

González Roa, Fernando y José Covarrubias, 1981, El problema rural de México. SRACEHAM, México, D.F.

Gudiño Cejudo, María Rosa, 2000, El Soconusco, el café y la colonización extranjera: 1875-1910. Tesis de licenciatura. ENAH, México, D.F.

Holden, Robert M., 1988, "Terrenos baldíos y usurpación de tierras". En Historia de la cuestión agraria mexicana; tomo 2, La tierra y el poder, 1800-1910, coordinado por Enrique Semo. Editorial Siglo Veintiuno, México.

Mejía Fernández, Miguel, 1979, Política agraria en México del siglo XIX. Editorial Siglo Veintiuno, México, D.F.

Molina Enríquez, Andrés, 1986, La revolución agraria de México, 1910-1920, tomo IV. UNAM-Porrua, México, D.F.

Orozco, Wistano Luis, 1911, La cuestión agraria. ed. tip. El Regional, Guadalajara, México.

Paulat Legorreta, Jorge, 1966, "El poblamiento del Soconusco. Sus antecedentes históricos y sus raíces socio-económicas". Revista ICACH, núm. 16-17, Tuxtla Gutiérrez.

Pedrero Nieto, Gloria, 1985, "San Cristóbal y Tuxtla, capitales de Chiapas en el Siglo XIX". Deslinde, Revista de la Facultad de Filosofía y Letras, vol. IV, núm. 10-11, mayodiciembre. México, D.F.

Silva Herzog, Jesús, 1980, El agrarismo mexicano y la Reforma Agraria. Exposición y crítica, 4. ${ }^{a}$ edición. Fondo de la Cultura Económica, México, D.F. 
Tannenbaum, Frank, 1929, Mexican agrarian revolution. Brookings Institute, Washington D.C. New York.

Wasserstrom, Robert, 1977, "La tierra y el trabajo agrícola en la Chiapas central: un análisis regional". Revista Mexicana de Sociología, vol. 39, núm. 3, México, D.F.

\section{Notas}

${ }^{1}$ Los casos de controversias jurídicas entre comunidades y propietarios sobre tierras que no tenían como punto de origen su denuncio como baldías, sino que surgieron por indefinición de límites o simple usurpación de tierras, no eran responsabilidad del juez de distrito (por no ser delito federal y por carecer de un interés del fisco federal). Estos casos se encuentran en los archivos de los diferentes juzgados de primera instancia del Poder Judicial Estatal.

${ }^{2}$ Gobierno del Estado de Chiapas, 1878, Colección de leyes agrarias y demás disposiciones que se han emitido con relación al Ramo de Tierras, pp. 3-17. Imprenta Joaquín Armendáriz, sin lugar. “Art. 1. ${ }^{\circ}$ Todos los terrenos baldíos o nacionales y de propios excepto los ejidos necesarios de los pueblos, se reducirán a propiedad particular" (1.9.1826); se establece que los ayuntamientos elijan y midan sus dos porciones de ejido antes de cualquier medida de particulares en la zona (1.9.1827). Si por posesiones particulares resulte un perjuicio al ejido, le será medido una tercera parte más que según su población le corresponda (19.1.1844). Se decreta la cantidad de tierras que le corresponde al ejido conforme a su población (28.1.1847). Se declara que los ejidos no deben tomarse fuera de la jurisdicción de cada pueblo; se prohíbe el establecimiento de labores o crianzas en el ejido y se obliga a los ayuntamientos a repartir lotes destinados a la población (24.3.1847). Para completar los ejidos, el gobierno promueve la venta de propiedades colindantes a cambio de una indemnización correspondiente (24.5.1849).

${ }^{3}$ Las propiedades de la familia Larráinzar, conformadas por adquisición de tierras comunales en los años cuarenta, que abarcaban gran parte de los municipios alteños de Chamula, Mitontic, San Andrés, Chenalhó, Pantelhó, Huistán, Chanal y San Carlos, fueron nuevamente fraccionadas después de pocos años, vendiendo grandes extensiones a los comuneros, que las adquirieron en mancomunidad. Cfr. Juzgado de Distrito (JD)Chiapas (Chis). Expediente 650. Año 1861. El C. Tomás Pérez y socios denuncian los terrenos contiguos a los ejidos del pueblo de San Carlos del Departamento de Comitán; "Amparo promovido en el Estado de Chiapas por los Sres. Ing. Carlos Z. Flores y Martín Morales contra una sentencia de la 2a Sala del Supremo Tribunal de dicho Estado, que declaró indivisa la Finca Chempil y absolvió a los demandados en juicio de reivindicación de la obligación de desocupar el inmueble”. México, 1909.

${ }^{4}$ Para autores que investigaron este fenómeno en el ámbito nacional: Orozco, Wistano Luis, 1911, La cuestión agraria, p. 27. Guadalajara; Molina Enríquez, Andrés, 1986, La revolución agraria de México, 19101920, tomo IV, México, D.F.; en términos generales el autor mantiene: “... las leyes de tierras baldías ... despojaban implacablemente a los mestizos y a los indios, de las escasas porciones que los primeros habían podido adquirir, y que los segundos habían logrado defender", siendo afectados "noventa y cinco por ciento de los pueblos indios", pp. 85-88; González Roa, Fernando y José Covarrubias, 1981, El problema rural de México, p. 36. SRA-CEHAM, México, D.F.; los autores mantienen que la ley de colonización de 15 de diciembre de 1883 “... sirvió en gran parte para preparar la revuelta actual, porque ha monopolizado de nuevo el territorio nacional despojando a muchos para enriquecer a pocos”; Mejía Fernández, Miguel, 1979, Política agraria en México del siglo XIX, pp. 252-255. Siglo Veintiuno, México, D.F.; González Navarro, Moisés, 1985, "La vida social”. En Historia Moderna de México. El Porfiriato, Cossío Villegas, Daniel. México, Buenos Aires, 4a ed.; el autor cita varios casos de compañías deslindadoras usurpando tierras comunales en el centro y norte de la república, pp. 188-189; Tannenbaum, Frank, 1929, Mexican agrarian revolution, p. 151. Washington D.C.; Silva Herzog, Jesús, 1980, El agrarismo mexicano y la Reforma Agraria. Exposición y crítica. Fondo de Cultura Económica, México D.F., 4a ed., en referencia al efecto que han tenido las compañías deslindadoras a escala nacional dice, "cometieron toda clase de arbitrariedades y despojos, en particular tratándose de pequeños propietarios y pueblos de indígenas que no poseían títulos perfectos ... Los tribunales, por supuesto, fallaban siempre a favor de los poderosos”, pp. 117-118; Fujigaki Cruz, Esperanza, 
1988, "Las Rebeliones campesinas en el Porfiriato". En Historia de la cuestión agraria mexicana, tomo 2, La tierra y el poder, 1800-1910, coordinador Enrique Semo, p. 218. México, a pesar de enfatizar las diferencias en los procesos de la formación de las haciendas en las diferentes zonas geográficas de México, la autora hace constar que el Estado "hizo muy poco para respetar los derechos de los campesinos sobre sus tierras, agua y bosques". Ferrer, Manuel, María Bono, 1998, Pueblos indígenas y Estado nacional en México en el siglo XIX, Instituto de Investigaciones Jurídicas, Serie C: Estudios Históricos, núm. 79. UNAM, México, D.F.; los autores presentan en el capítulo VI, "El Problema de la Propiedad Comunal", un interesante repaso de las informaciones circulantes durante el siglo XIX sobre la problemática de la desamortización de las tierras colectivas, ubicándolas en su contexto de las diversas leyes federales y estatales.

Autores que investigaron este fenómeno para el estado de Chiapas: Holden, Robert M., 1988, "Terrenos baldíos y usurpación de tierras". En Historia de la cuestión agraria mexicana, tomo 2, La tierra y el poder, 1800-1910, coordinado por Enrique Semo, pp. 269-289. México; el autor no solo demuestra con base en la documentación de la Secretaría de Fomento que la usurpación por parte de la compañía deslindadora de las tierras colectivas de las comunidades nunca tuvo lugar, de igual modo comprueba que más bien las compañías deslindadoras se quejaron de los jueces federales, diciendo que favorecieron a los tenedores de tierras locales, p. 282; González de Cossío, Francisco, 1981, Historia de la tenencia y explotación del campo desde la época precortesiana hasta las leyes del 6 de enero de 1915, tomo I, SRA-CEHAM, México, D.F.; el autor presenta el caso de un decreto en 1878 del gobierno federal respecto a los ejidos de Chiapas, que busca una fórmula especial para que se pueda cumplir con los preceptos de las Leyes de Reforma, proponiendo que se designen los terrenos necesarios a los pueblos que no los tuvieran, fraccionándolos inmediatamente conforme a ley, p. 175; Wasserstrom, Robert, 1977, "La tierra y el trabajo agrícola en la Chiapas central: un análisis regional”. Revista mexicana de Sociología, vol. 39, núm. 3, pp. 1043-1045. México, D.F.; Peña, Moisés T. de la, 1954, Chiapas económico, 4 tomos. Tuxtla Gutiérrez; Benjamín, Thomas Louis, El camino a Leviatán. Chiapas y el Estado mexicano, 1891-1947, pp. 72-74; Favre, Henri, 1984, Cambio y continuidad entre los mayas de México. Contribución al estudio de la situación colonial en América Latina, Colección INI, núm. 69, 2. ${ }^{a}$ edición, pp. 67-78. México, D.F.; el autor, aunque da una descripción drástica de la pérdida de los terrenos colectivos a manos de los propietarios, confiesa: "Es difícil traducir a cifras la amplitud del fenómeno cuyas características generales acabamos de esbozar, en primer lugar porque se han conservado muy pocos documentos públicos o privados, y después porque los muy raros textos que han llegado hasta nosotros nunca indican la superficie de las tierras acaparadas"; García de León, Antonio, 1985, Resistencia y Utopía. Memorial de agravios y crónica de revueltas y profecías acaecidas en la provincia de Chiapas durante los últimos quinientos años de su historia, dos tomos, pp. 157-174 del tomo I. Ediciones Era, Colección Problemas de México, México; Paulat Legorreta, Jorge, 1966, "El poblamiento del Soconusco. Sus antecedentes históricos y sus raíces socio-económicas". Revista ICACH, núm. 16-17, pp. 87-97. Tuxtla Gutiérrez; el autor mantiene que la Compañía Inglesa de Terrenos sí respetó las tierras comunales, pero que posteriormente, el gobierno de Emilio Rabasa los deslindó y los vendió; Pedrero Nieto, Gloria, 1985, "San Cristóbal y Tuxtla, capitales de Chiapas en el Siglo XIX". Deslinde, Revista de la Facultad de Filosofía y Letras, vol. IV, núm. 10-11, may-dic., pp. 65-66. México, D.F.; la autora presenta el caso de las tierras comunales en Los Altos de Chiapas, donde el gobierno del estado toma partido en favor de las comunidades contra los hacendados, pero tiene que rendirse frente a la presión de los hacendados sancristobalenses en 1893.

Para el decreto de 6 de enero de 1915 de Venustiano Carranza: Fabila, Manuel, 1990, Cinco siglos de legislación agraria (1493-1940), 2a ed , pp. 228-232. SRA-CEHAM, México.

${ }^{5}$ En 1863, en un hecho insólito, dos grandes archivos fueron víctimas de las luchas entre las tropas al mando de Juan Ortega y fray Víctor Chanona, leales al imperio francés, y las tropas del gobierno de Benito Juárez, atrincheradas en el centro de la ciudad de San Cristóbal durante los meses de mayo y agosto de 1863. En sus intentos por desalojar a las tropas republicanas los imperialistas incendiaron primero la casa consistorial el 5 de mayo, sede del gobierno municipal de la ciudad y ubicada sobre el lado poniente de la plaza principal, tres meses más tarde redujeron a cenizas el palacio de gobierno, sede de los poderes del estado, sobre el lado nororiente de la misma plaza. "El cuartel, la Casa Consistorial, el Palacio de los Supremos Poderes y manzanas enteras contiguas a la plaza, se hallan reducidas a cenizas y escombros" (El Espíritu del Siglo, t. IV, núm. 86, 4.4.1868, p. 4). En ambos incendios desaparecieron valiosos fondos documentales, sobre cuyo contenido solo podemos especular.

${ }^{6}$ Holden, Robert H., op cit., p. 282.

${ }^{7}$ Investigación llevada a cabo por el autor de este ensayo, durante los años 2003-2006. 
${ }^{8}$ En este caso se trata de la correspondencia de la Secretaría de Fomento intercambiada con el juez de distrito, que fue localizada en los expedientes de denuncios. Los resultados aquí presentados deben ser considerados como preliminares por faltar revisar la sección de amparos del propio Juzgado de Distrito y, más importante, por faltar una investigación detallada de los archivos judiciales del poder judicial del estado y de los archivos de los ayuntamientos y comunidades.

9 Actualmente el autor está desarrollando una investigación con fuentes primarias sobre "La llamada compañía inglesa en Chiapas, 1886-1917", que le ha obligado a revisar detenidamente los archivos del Juzgado de Distrito de Chiapas, logrando como resultado colateral la formación de un banco de datos acerca de la tenencia de la tierra en el siglo XIX.

${ }^{10}$ Véase nota de pie de página número 1

${ }^{11}$ Con excepción de la titulación de los lotes individuales de los antiguos ejidos, que correspondía a la Secretaría de Fomento, todos los demás asuntos relacionados con los terrenos colectivos (ejidos), como solicitudes de dotación, medidas, ampliación, casos de invasiones o despojo, correspondían a los juzgados de primera instancia y al gobierno del estado.

${ }^{12}$ Cfr. Decreto del presidente López de Santa Anna de 25.11.1853. Colección de leyes agrarias y demás disposiciones que se han emitido con relación al Ramo de Tierras, 1878, Mandadas a reimprimir de (sic) orden del superior gobierno del Estado, Imprenta del Gobierno, s/l, pp. 16 ss.

${ }^{13}$ Hay casos de denuncios en años posteriores que fueron canalizados al Juzgado de Distrito a través de los agentes de tierras baldías, dependientes del Ministerio o de la Secretaría de Fomento, quienes fungían en diferentes departamentos del estado. No obstante, la mayoría de los denuncios fue enviada directamente al juez de distrito.

${ }^{14}$ De facto, el manejo de los denuncios de tierras nacionales o baldías regresó a las autoridades chiapanecas durante los años 1862 hasta 1867, no por disposición del imperio francés, sino por la casi completa incomunicación entre el gobierno de Benito Juárez y el gobierno del estado, fiel a la causa liberal, por motivo de la guerra. Los expedientes de estos años fueron concentrados en el archivo del Juzgado de Distrito, formando parte del actual acervo.

${ }^{15}$ Fueron incluidos los casos de 1876, a pesar de que el general Porfirio Díaz se instaló a finales de ese año en el poder, por considerar que en la mayoría de los expedientes, las acciones jurídicas que definieron el curso de los casos fueron iniciadas y realizadas apenas en 1877.

${ }^{16}$ Cfr. Disposición suprema de 26 de marzo de 1878. Referente al estado de Chiapas. Legislación y Guía de Terrenos Baldíos, 1878, Díaz Leal, José, pp. 32 ss. Imprenta de Francisco Díaz de León, México. Este decreto renueva la obligación de remedir y fraccionar en lotes a los ejidos; Ley de colonización y terrenos baldíos, del 15 de diciembre de 1883. En Legislación de terrenos baldíos, 1892, de la Torre, Juan, pp. 38 ss. Imprenta del Gobierno, Morelia. Esta ley autorizó el deslinde de los terrenos baldíos por parte de las compañías deslindadoras; Circular de 28.10.1889 de la Secretaría de Fomento, ordenando el reparto de los terrenos de repartimiento. En Ferrer, Manuel y Bono, María, op. cit., p. 471; Dublán, Manuel y Lozano, José María, 1894, Legislación mexicana, vol. XXIV, núm. 12516, pp. 35-45. México; esta ley reforma la de 1883, se elimina la restricción de solo poder denunciar 2,500 hectáreas por individuo.

${ }^{17} \mathrm{El}$ faltante de once denuncios se refiere a casos que fueron remitidos a juzgados de primera instancia, por no ser de competencia del JD.

${ }^{18}$ Con frecuencia los títulos ya no se encontraban en manos de las autoridades interesadas porque se habían extraviado o quemado; la única opción de comprobar sus derechos era la de encontrar copia del título en el archivo de la secretaría de gobierno o alguna prueba fehaciente en los archivos judiciales del estado o de la federación.

${ }^{19}$ Por ejemplo: Carmen Trujillo denuncia dos porciones de terrenos baldíos denominados Chitaltic y Atajasil, ubicados en el Departamento de Chilón, fs 4. JD-Chis. Expediente 23 (rojo). Año 1878-3.

${ }^{20}$ Para este último caso ver, por ejemplo: Rafael López denuncia un terreno baldío ubicado en el Departamento de Tuxtla, Ocuilapa, JD-Chis. Expediente. 23. Año 1876-1; Aristeo López denuncia un terreno baldío ubicado en el Departamento de Tuxtla, JD-Chis. Expediente 271. Año 1879-2; Fidel Tirado denuncia el excedente de terreno baldío que resulte en la remedida del ejido del pueblo de Zintalapa, del Departamento de Tuxtla, JD-Chis. Expediente 256. Año 1879-2.

${ }^{21}$ Damián Cal y Mayor denuncia un terreno baldío ubicado en el valle de Zintalapa del Departamento de Tuxtla, JD-Chis. Expediente 268. Año 1879-2; José Francisco Salvatierra denuncia un terreno baldío ubicado en el Departamento de Pichucalco, JD-Chis. Expediente 233. Año 1881-1.

${ }^{22}$ También conocida como Ley Lerdo. 
${ }^{23}$ Aunque legalmente los vecinos no podían aprovechar los productos de los terrenos en litigio, las quejas presentadas por los denunciantes al JD, dejan ver que a pesar de las amonestaciones hechas por el juez a los vecinos, ellos seguían explotando las milpas y recursos maderables. Cfr. JD-Chis. Expediente 107. Año 18662. El presbítero D. Luis B. Villatoro denuncia el terreno Concepción sito en jurisdicción del pueblo de Amatenango, en 1884 el denunciante se queja de que los vecinos de Amatenango siguen usando el terreno; JD. Expediente 52. Año 1878-3; Aristeo Rodríguez denuncia un terreno baldío ubicado en el Departamento de Tuxtla Gutiérrez; JD-Chis. Expediente 294. Año1881-2; David José Narváez denuncia un terreno baldío nombrado Tuenó, Comicoshoc, Yocshapiac y Nanchinbac, ubicado en el Departamento de Tuxtla; JD-Chis. Expediente 273. Año 1881-2; El Sr. Manuel Días Innureta denuncia el terreno denominado La Posa en el Departamento de Palenque.

${ }^{24}$ Como la Constitución de 1857 no mencionaba los ejidos entre los bienes permitidos a los pueblos, tal como lo hacía el artículo 8 de la Ley de junio de 1856, esto llevó en varios casos a la venta de los mismos a particulares. Cfr. Ferrer, Manuel y Bono, María, op. cit., pp. 466-471.

${ }^{25}$ Ferrer, Manuel y Bono, María, op. cit., pp. 473 ss.

${ }^{26}$ El promotor fiscal Mariano Aguilar, a la postre gobernador del estado, declara el 30.4.1878: "aunque no puedo dejar de manifestar de paso, que en los juicios como el de que nos ocupamos, jamás se ha puesto en duda la personería de los Síndicos de los Ayuntamientos como podrá verse en las muchas despachadas por el Juzgado de su merecido cargo". En Juicio de oposición seguido entre el Ayuntamiento de Istapa y el Señor Julián Constantino con motivo del denuncio que este hizo del terreno Paxamuntic, fs 60, JD-Chis. Expediente 37.

27 Véase, Mariano Reinoso denuncia el ejido del pueblo de Santa Catarina Huitiupán, fs 7, JD-Chis. Expediente 172. Año 1884-2.

${ }^{28}$ Y más aún entre los casos que fueron declarados desistidos.

${ }^{29}$ Véase el caso del Sr. Fermín Romero, hermano de Matías Romero, quien pierde en 1882 en el Juzgado de Circuito el juicio de oposición iniciado de parte del ayuntamiento de Unión Juárez. Cfr. Juicio de oposición promovido por el Lic. Juan Félix Zepeda como apoderado del H. Ayuntamiento de Unión Juárez sobre el terreno excedente denunciado por el Sr. Isidro de León, JD-Chis. Expediente s/n. Año 1892. En denuncios de Manuel Domingo Coello, Guadalupe Coello Lara y Manuel Pineda, todos miembros de la clase política del estado en estos años, el JD declara su desistimiento. Cfr. JD-Chis. Expediente 295. Año 1879-2; JD-Chis. Expediente 189. Año 1884-2; JD-Chis. Expediente 188. Año 1884-2.

${ }^{30}$ Es preciso aclarar que no todos los casos surgieron porque el denunciante insistía en denunciar terrenos en posesión efectiva de los comunitarios, sino más bien por la frecuente imprecisión de los títulos, hayan sido de los particulares o de los terrenos colectivos, respecto de mojones, colindancias y superficies amparadas.

${ }^{31}$ Cfr. Bartolomé Estrada, Melchor Jimenes y Jacinta Ramírez denuncian un terreno baldío ubicado en jurisdicción del pueblo de Bachajón, Departamento de Chilón, llámense Alumtenan, Alamquinal y Chalamchen, JD-Chis. Expediente 35. Año 1876-1; Sebastián Ruiz denuncia un terreno nacional contiguo a su finca llamada San Vicente Arroyo del Zapote, sito en el Departamento de Chiapa, JD-Chis. Expediente 58. Año 1876-2; al informar, el agrimensor argumenta contra el denunciante, diciendo que el terreno estaba en posesión de muchos indígenas; Sres. Gregorio Estrada y Máximo Pérez denuncian un terreno baldío ubicado en el pueblo de Coapilla del Departamento de Tuxtla Gutiérrez, JD-Chis. Expediente 270. Año 1881-2; frente a un denuncio de 1,284 hectáreas de ejido, el agrimensor se niega a la medida, porque "los ejidos no pueden adquirirse en propiedad particular"; Rafael Albores denuncia el excedente baldío que haya dentro y fuera de la cabida de su finca de propiedad denominada Naqutuncul, sita en el Departamento de Comitán, JD-Chis. Expediente 262. Año 1883; el agrimensor acepta los mojones indicados por el pueblo, a pesar de no coincidir con el plano, "para alejar las dificultades".

32 Paciana Utrilla de Morales denuncia un terreno baldío sito en el municipio de Copainalá denominado Naranjal, Departamento de Tuxtla, JD-Chis. Expediente 284. Año 1881; Anastacio Palacios denuncia un terreno baldío denominado Seival en el Departamento de Simojovel, JD-Chis. Expediente 184. Año 1881-1.

${ }^{33}$ Periódico Oficial de Chiapas, núm. 19, 10.4.1886, p. 2, Secretaria de Fomento, Colonización, Industria y Comercio, Sección 1. a , circular.

${ }^{34}$ Datos del Archivo Histórico del Poder Judicial Federal, Casa de la Cultura Jurídica, Tuxtla Gutiérrez, Chiapas, años 1827-1886, Ramo Civil, Denuncios de Tierras Baldías.

${ }^{35}$ Íbid. 
${ }^{36}$ Periódico Oficial de Chiapas, núm. 1, 6.12.1884, p. 1, Gobierno General; Circular de la Sección 1. a de Fomento a los Jueces de Distrito; Periódico Oficial de Chiapas, núm. 12, 23.2.1884, p. 3, Crónica Parlamentaria, 29.10.1883.

${ }^{37}$ SRA/ATN. Chiapas. Deslindes. 1.71(05). L. 3. E. 55. Liquidación de los terrenos deslindados por la Compañía de Terrenos y Colonización y permuta de terrenos de Sonora por terrenos de Chiapas.

${ }^{38}$ JD-Chis. Civil. Expediente relativo al deslinde de terrenos del Estado por la Compañía Luis Huller y Cía, exp. 2/886, inició 2.8.1886.

39 Peña, Moisés T. de la, 1954, Chiapas económico, tomo II, p. 354. Tuxtla Gutiérrez; Wasserstrom F., Robert, 1977, "La tierra y el trabajo agrícola en la Chiapas central: un análisis regional". Revista Mexicana de Sociología, vol. 39, núm.3, p. 1044. México, D.F.; Gudiño Cejudo, María Rosa, 2000, El Soconusco, el café y la colonización extranjera: 1875-1910. Tesis de licenciatura. ENAH, México, D.F.; Favre, Henri, 1984, Cambio y continuidad entre los mayas de México. Contribución al estudio de la situación colonial en América Latina, Colección INI, núm. 69, $2^{\text {a }}$ edición, p. 72. México, D.F.; Reyes Ramos, María Eugenia, 1992, El reparto de tierras y la política agraria en Chiapas, 1914-1988, pp. 35-36. Universidad Nacional Autónoma de México/CIHMECH.

${ }^{40}$ SRA/ATN. Chiapas. Diversos. 1.29(05). L. 5. Expediente 182. 1909.02.06, Vecinos del municipio de Juárez, Departamento de Pichucalco, se quejan contra la Compañía de Terrenos de Chiapas, México, Limitada; SRA/ATN. Chiapas. Diversos. 1.29(05). L. 5. Expediente. 208. Año 1914. Rómulo Ramos por sí y varios vecinos de la Rivera Hidalgo, municipio de Juárez, Departamento de Pichucalco, solicitan que la Secretaría intervenga ante la Compañía de Terrenos de Chiapas, con el fin de que se rebajen los precios de las tierras.

${ }^{41}$ Véase nota de pie de página número 4. 